\title{
Teacher education students' struggles with group work in service learning
}

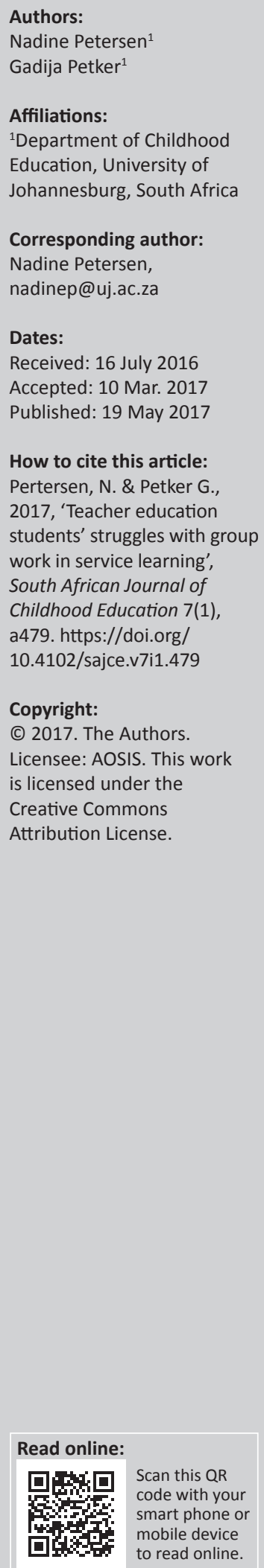

\begin{abstract}
This article reports on students' experiences of learning to work together in a childhood teacher education programme at a university in South Africa. We were interested in how students from diverse backgrounds, with little shared understanding of a model or framework for collaborative working, would find their footing and learn how to operationalise care, accountability and reflexivity through engaging in group work as part of their service learning activities. A cross section of student data, from first year to third year, was analysed using qualitative methods of data analysis. The main findings were that the incremental integration of service learning, with fixed student groupings over three years, was a catalyst for the gradual formation of professional student learning communities. The student struggles with group relationships helped them address their cultural, linguistic and gendered assumptions about each other. Lastly, we found that relatively fixed nature of the student groupings over a three year period encouraged deep reflection about ideas of care, community and social responsibility.
\end{abstract}

\section{Introduction}

This article reports on a cross section of students' experiences of learning to work together in a new childhood teacher education programme at a large comprehensive university in South Africa. In particular, we were interested in how students from diverse backgrounds, with little shared understanding of a model or framework for collaborative working, would find their footing and learn how to operationalise a faculty framework of care, accountability and reflexivity through engaging in group work as part of their service learning (SL) activities.

The value of SL for student learning has long been the subject of investigations in the field of teacher education internationally. Based on the first author's research incorporating SL into a secondary school teacher education curriculum, we have designed a childhood teacher education programme to incrementally infuse SL into the first three years (Petker \& Petersen 2014). This move is also in line with the new teacher qualification framework (DoE 2011), with its emphasis on students' learning in and from practice in order to develop tacit knowledge for the world of teaching. Although there are a few examples of how SL has been integrated into teacher education programmes in South Africa (Castle \& Osman 2003; Mitchell \& Rautenbach 2005), research on SL in foundation phase teacher education programmes is very sparse.

We also focus on students' reports of their struggles with learning to work together during SL. We argue that there is value in students' struggles with establishing a sociocultural 'community of practice', which requires them to become simultaneously part of a 'cognitive apprenticeship' and a 'caring apprenticeship' with others in their group. Successful group work in SL, in our view, promotes the development of a sense of community and an ethic of care traits we argue are essential for prospective teachers.

\section{Framing student learning through service learning in a sociocultural community of practice}

There is compelling evidence in the research literature in teacher education in the USA that SL has positive effects on student personal and interpersonal development and their ability to work well with others (Eyler et al. 2001; Wang 2000). SL is also credited with the development of leadership and communication skills (Raskoff 1997; Vogelgesang \& Astin 2000) and its ability to reduce stereotypes and facilitate cultural and racial understanding (Boyle-Baise \& Kilbane 2000). Research also illustrates how SL fosters the collaboration skills and dispositions relevant to being an effective teacher (Rowls \& Swick 2000). In particular, we draw on literature that deals with addressing the need to enhance students' understanding of caring and the development of caring dispositions and behaviours (Noddings 1992; Swick \& Brown 1999) and that which studied how 
to socialise teacher education candidates into the civic and caring components of being a teacher (Freeman \& Swick 2001). Lastly, we draw on arguments forwarded by SL researchers and practitioners that 'incremental integration' (Berle 2006) can lead to more successful SL experiences for students and staff. We found particularly useful Zlotkowski's (1999:101) conceptual matrix for building progressively more complex forms of service engagement while explicating the intersection of student and academic interests. The matrix unpacks academic presence to include a continuum from expertise to concern for the common good and student domain to incorporate both the classroom and the world beyond the classroom.

These rationales have informed our approach to SL (Morton 1996) in the foundation phase teacher education curriculum. It is also in keeping with our underlying philosophical perspective of SL as an 'inductive, process-based' pedagogy in which student experience and voice are central and our epistemological position which recognises the centrality of student's learning as a result of their experiences and how this is a valuable form of knowledge (Henning 1997). As such, it acknowledges and validates students as active contributors to their own learning and thus to the process of knowledge production.

Theoretically, we also draw on two strands of socioconstructivist theories of learning, in particular that of communities of practice (CoP), first coined by Lave and Wenger (1991) in their study of apprenticeship as learning model, and that of situated cognition. ${ }^{1}$ Wenger in his later work (2014) argues that the term CoP is not limited to a novice learning primarily with or from a master; he proposes instead that because of the dynamic nature of the $\mathrm{CoP}$, everyone in the endeavour learns. In his view, 'communities of practice are groups of people who share a concern or a passion for something they do and learn how to do it better as they interact regularly'. Within this definition, three elements are vital and have to be developed in parallel so that a community of practice is cultivated: (1) The domain: Membership in a CoP identifies with commitment to a shared domain of interest, and therefore a shared competence. In other words, members have to (learn to) value their collective competence and learn from each other, even though few people outside the group may value or even recognise their expertise. (2) The community: In pursuing their interest in their domain, members engage in joint activities and discussions, help each other and share information. Thus, they build relationships that enable them to learn from each other. (3) The practice: Members of a $\mathrm{CoP}$ are practitioners. In short, they develop a shared practice wherein they develop a shared repertoire of resources: experiences, stories, tools and ways of addressing recurring problems. All of these take time and sustained interaction and are often more or less self-conscious;

1.Situated cognition as we use it is based on the writing of Brown, Collins and Duguid (1989). These scholars acknowledge that their theorising draws on the research of activity theorists such as Vygotsky, Leontiev and others in the field, on the work of Rogoff and Lave, Engeström, Lave and Wenger and, in particular, on the work by Rogoff and Lave,
Lave herself. in investigating student experiences of this process over three years, we hoped to make the process more explicit.

From the theoretical stand on situated cognition, we find particular support for understanding the process of learning in service learning and its contribution towards building a community of practice. The main premise of situated cognition is that knowledge cannot be extracted from the situations in which it is learned and used. Thus, 'situations ... co-produce knowledge through activity', thereby rendering activity and situation integral to the processes of meaning making (cognition and learning) (Brown, Collins \& Duguid 1989:1). These authors also argue for cognitive apprenticeship to enculturate students into an authentic practice by activity and social interaction. Here, the key features are the situated nature of knowledge and becoming part of a sociocultural 'community of practice'.

Applied to an SL context with teacher education students, the significance of situated cognition for thinking about the process and situation of learning is in how the social context of SL influences the culture and nature of their learning and understanding. Through the pedagogy of service learning, students, through enacting their service in authentic contexts, are encouraged to move into and engage with the constituent elements of the situation in which their learning occurs - they learn about the world by being in the world and reflecting on it. We claim that the SL context provides all the contextual features of an authentic task (Brown, Collins \& Duguid 1989) and it enables students to engage with more than just the peripheral features of tasks as would often be the case if they were confined solely to university-based classroom activities. For student teachers, this aspect is of particular significance as they learn to integrate reflective forms of personal and professional knowledge with academic knowledge and understand the implications thereof for practice.

\section{Context of the study: Service learning within a foundation phase teacher education programme}

The SL activities in the foundation phase programme were designed to inform and draw on students' practical learning (learning in practice) in an authentic classroom or school environment and their situational learning (learning in and about context) (DoE 2011). Service is offered to children at a university-affiliated Soweto teaching or laboratory school and to the wider Soweto community. Students work with the same peers in racially and linguistically diverse groups of 10 from the first to third year of study. In order to strengthen the students' learning about care and community as part of becoming a teacher, SL is integrated throughout the first three years of their programme, with each section playing a very specific role. The integration of SL is informed by studies that argue for coherence and progression of students' learning about concepts and practices associated with care and community in whole programmes (see, for instance, Darling-Hammond 2006; Moule 2005) and those that argue that the duration and intensity of service have a direct impact on student outcomes (Astin \& Sax 1998). 
Thus, in the first year of the programme, the SL activities are aligned with teaching as the practice of caring citizenship (Freeman \& Swick 2001). Here, students focus on the planning and execution of an event at the teaching (lab) school. In the second year, students work on an antibullying campaign in which they design a series of interactive plays and games towards this end, based on their academic knowledge of how children interact socially with their peers. The third year consists of an SL project in which the focus is on using children's literature and storytelling. The students' activities extend beyond the teaching (lab) school to incorporate the wider Soweto community, where the focus is service to the wider Soweto schooling sector. Research into various aspects of this integration has been captured elsewhere (Gravett, Petersen \& Petker 2014; Petker \& Petersen 2014). Here, we explore students' reports of their struggles with learning to work in group format during their SL.

\section{Research methods and design}

A cross-sectional, qualitative research design was used because we investigated first-, second- and third-year students' accounts of their experiences or struggles of collaborative work during the SL projects. The choice of a cross section of students was motivated by the need to understand what each student grouping struggled with, how an incremental model for infusing SL influences students learning and development over time and how these influenced their learning about becoming foundation phase teachers. As researchers, we were interested in the process (the how, where, when and why of students' experiences) (Henning, Van Rensburg \& Smit 2004; Merriam 2002a). The data sources included reflective journals, photographs and video recordings of students during their SL activities. In addition, third-year students completed a questionnaire covering aspects of their service project (such as group dynamics).

We analysed the written data through a two-part process of coding and categorising working with a form of open coding (Babbie \& Mouton 2015; Henning et al. 2004; Merriam 2002b) in combination with a search for markers in the student's discourse and actions informed by the main theoretical frame of CoP. In particular, we looked for signifiers of students' struggles with how to work and engage with each other collaboratively in their reflective accounts and the solutions they found in the absence of a teacher-educator-led model. The first stage of this was completed by the two authors individually and, thereafter, the authors discussed the analysis and began to link comparable views and concepts. The photographs and videos were analysed using protocols, designed from Henning et al.'s (2004) qualitative data analysis procedures. Visual data analysis was also informed by methods used in educational research in South Africa (De Lange, Mitchell \& Stuart 2007). Video data were particularly useful for capturing students' interactions with each other (FitzGerald 2012) and were mainly used to corroborate findings from the first part of the analysis process.

\section{Findings of the study}

The main pattern that we constructed from this investigation was that the incremental integration of SL, with fixed student groupings over three years, resulted in the gradual formation of professional student learning communities. The data indicated that students struggled with group relationships but that it helped them address their cultural, linguistic and gendered assumptions about each other. Lastly, we found that the relatively fixed nature of student groupings over a three year period encouraged reflection about ideas of care, community and social responsibility.

\section{Group work builds professional learning communities}

In our early work with students in this programme, we assumed that most had ample exposure to group work from school level and would naturally bring this experience into their first-year university courses. However, our early experiences showed that first-year students struggled with the idea of collaborative working with many reporting that they had 'not explicitly been taught the skills and strategies to work together as a team'. As a department, we thus deliberately facilitate group-working relationships on their entry to university. We create relatively fixed, mixed (language, race, gender) groups of students which persist up to fourth-year level and are the basis for all activities in the programme. In these groups, students are specifically taught how to work together. In addition, the second author as first-year course teacher, together with senior tutors, spends considerable time in the first semester preparing students for teamwork. Despite these measures, we found that students still report that they find the group work challenging.

A huge part of students' struggles in this respect can be traced to their individual differences and the disjuncture between academic expectations at school level in comparison with university. For instance, the differing work ethic of students is one such challenge. This also impacts other aspects such as student responsibility and time management. The latter was a particularly contentious issue, with the majority of students in both first and second year reporting that:

'time management was a major problem because we had to work in a group. Some members would come late to meetings or not do their share of the work. It was a great frustration because then our project plan and time frames would be out of sync.' (1st Year student)

It also affects expectations of what constitutes professional work as a teacher education student. In this respect, the following student comment is relevant:

'I did not like the way some of the members in my group presented their work and how they viewed their roles as future teachers. I am very professional when it comes to my work and the presentation of it and some of them did sloppy work. This made me angry.' (2nd Year student) 
The process of resolving these kinds of issues and conflict in order to plan and execute the SL project successfully meant that students had to learn to compromise on expectations, be accountable to the group and to care and guide each other in a way that they had not previously been expected to. This is captured by the following student comment:

'I had to learn to be more humble, to take the criticism of my work ethic and to learn to be more accountable and critically reflective.' (1st Year student)

Importantly students had to learn that they had a responsibility to share their ideas about what constituted acceptable professional work and see the value in group members' contributions in order to be able to execute their SL projects. The following student comments describe this:

'I learned that I must be willing to walk the talk, care for my peers and respect them and their viewpoints.' (1st Year student)

'There were times that we did not agree on ideas or issues. Sometimes our disagreements were not friendly but we had to learn to give in to one other and deal with our issues in more caring ways. We had to learn to resolve our differences and work toward making our project a success.' (2nd Year student)

In some cases, the lecturer's or tutor's intervention was required to get students back on track:

'I went to my lecturer and she guided me to thinking differently and approaching the problem in a more positive way so I am less irritated. She made me see that I need to inform my peers of the frustrations I have so they are aware of how I feel. I did this and things got better. I still see now how I will encounter similar problems in the future; it's just about how I deal with it.' (1st Year student)

Evident in the data was that students grew as individuals and were also learning to become part of a community of practice:

'I had to work with other students in my SL group. At first, I was not happy to work with strangers or other people but during and after the SL experience I made friends and felt like I could turn to my peers for assistance.' (3rd Year student)

The individual CoP developed very organically with each group of 10 students constituting their own rules of engagement. Three specific examples are illustrative hereof. One first-year group worked with penalties for breaking group rules, particularly with respect to lateness and not completing the assigned tasks. This group described these measures as their 'rules for group participation so that we get the job done on time'. The group reported that:

\footnotetext{
'If members broke rules they had to be penalized in the form of losing marks or paying a small monetary fine. This fine would then go into the group fund and contribute toward the purchasing of items for the service learning activities. This motivated group members to be more committed and understand their responsibilities.' (1st Year student)
}

A first-year group struggled with communication during group meetings. To combat some members dominating the discussions, the group fashioned a fake microphone to:
'Allow for all group member voices to be heard. If you had the 'microphone' in your hand, no one else could talk. We also learned to respect the value of silence ... someone doesn't need to be talking all the time ... and listening with respect when someone else is talking.' (1st Year student)

A third group turned to social media with a WhatsApp chat group so that all:

'Members got a chance to speak and share their opinion. It also cut down on travelling time ... we didn't need to be at the university campus at the same time to share ideas.' (3rd Year student)

Towards the second year, students began to realise that their working together as a team was essential if they were to contribute effectively to their service initiatives in the community. One second-year student said:

'I had to learn to get along with others and to work as a team. Otherwise, the project will fail. If that happens I am not of any benefit to our society and our children.' (2nd Year student)

Another student in the second year noted that reflection as part of the SL created opportunities for introspection:

'The service learning experience made me look deep into my own personality and character traits ... so that I don't blame other people for what goes wrong. I have to take responsibility so that we can work together as a team towards the betterment of the community.' (2nd Year student)

Students also began to develop closer relationships outside of their academic peers and UJ lecturers. The community members in the form of the teaching staff became student mentors in their projects. This is captured in many students' reflections, as recounted in the following:

'I also had the courage to speak to the teachers at the school if I needed help or advice. I didn't see them as outsiders anymore, they have so much experience. They can help me become a better teacher.' (3rd Year student)

As group interactions improved so did students' growth in areas not generally associated with learning to become a teacher. One key issue was learning to become entrepreneurial. As funding is not provided for SL activities, students are required to raise funds for projects. All students reported that this was a huge learning curve as they had 'no previous experience at sourcing funding or approaching sponsors for donations' (1st Year student). Some groups turned to known networks 'to assist with contacts in the large corporate companies and small businesses for sponsorship' (3rd Year student), whereas others 'made use of recycled products to put together items they required for the events' (1st Year student). For the few groups who made use of the latter option, they report that:

'In collecting old items and recycling these into new and beautiful things for the children it brought the group closer and taught us the value of thinking outside the box and using things already available as opposed to sourcing money which is so scarce in our communities.' (1st Year student) 
This is also captured in the following two verbatim excerpts:

'Working together as a group ... we assisted each other with brainstorming sessions and pooled resources for our events.' (3rd Year student)

And:

'We were dependent on each other to make the event a success from planning, to resourcing, execution and reflection. We couldn't do this without the group'. (1st Year student)

\section{Crossing the cultural, linguistic and gendered divide}

A second finding is that the group work helped reduce stereotypes and facilitated more cultural and racial tolerance. In our experience of working with a very mixed group of students from multilingual and multiracial contexts, issues of race and communication present particular challenges for effective teamwork. It seems that despite our students being products of a democratic society, with an integrated schooling background, language, race and gender still impact student relationships with those who are different to them. In this respect, at the beginning, students report that:

'I never had exposure to working with people from different cultural backgrounds. Working in my service learning team forced me to interact with students from different cultural and racial groups and I also got a sense of what it meant to interact with community members from different cultural backgrounds.' (1st Year student)

As students stay in the same peer groups for the duration of their studies, we found these admissions at the beginning of their SL experiences valuable as a basis for encouraging the growth of CoP. In the cases where students approached sponsors for support, this issue also came to the fore:

'I got to interact with community members from different racial and cultural backgrounds because we had to approach them for sponsorships.' (2nd Year student)

Of particular importance was addressing 'language barriers'. Mixed raced students, ${ }^{2}$ indian students and white students who are unable to speak an African language fluently were at a decided disadvantage. In the early grades of the universityaffiliated Soweto teaching school, the dominant languages of the children are Sesotho and isiZulu. Thus, although all students take a beginning African language course of either Sesotho or isiZulu from their first year, it takes some time to develop language proficiency. At this teaching school, the Grade R learners in particular speak very little English and students rely on their black student peer group members to translate for them in their interactions with the children. One student reported: 'I could not understand the children because they spoke an African language so my peers had to help translate for me.' We have found that this situation shifts the boundaries of which students are seen to possess the

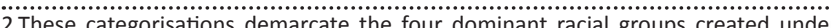
apartheid and are still commonly used for the purposes of equity in reporting by business, education business, educational institutions and other entities in South Africa. We use it here as a descriptor to aid understanding of the students' racial and language backgrounds as it impacts their learning in the programme. necessary cultural and academic capital for successful academic work. In particular, for many Black students in this programme, who often struggle to express themselves adequately in English, especially in their first year of studies, and generally come from disadvantaged schooling backgrounds, the ability to speak the language of the children in the teaching school now becomes a clear strength for the group. First language isiZulu or Sesotho students are valuable group members in the SL projects. For instance, the following quote from a white student is indicative hereof:

'I now see my peers in a different light ... they have strengths I didn't initially see. We would not be able to do our project at Funda UJabule ${ }^{3}$ without them.' (1st Year student)

It also heightened students' awareness of the connection between language and learning. For example, a student reported that being in a space where he didn't understand the children or the discussion taught him to place himself in the shoes of black students who struggle to express themselves in English:

'In discussions when the English first language students speak fast and don't see if the African students are keeping up ... I didn't realise how it impacts their learning until now.' (2nd Year student)

This also affected non-African language speakers' attitudes to learning basic/introductory isiZulu and/or Sesotho. Students generally struggle with this aspect of the foundation phase curriculum, and we have found that the SL helps change their attitudes about learning an African language there is less negativity associated with these language courses after the first SL event:

'I only now see the value of learning and understanding an African language .... not only to communicate with my peers and the children, but also their parents and other community members ... what if I get a job in a school where all the parents do not speak English?' (3rd Year student)

On the contrary, when black students dominated the group membership, and the conversations were conducted exclusively in either isiZulu or Sesotho, those students who do not speak one of these languages were 'completely left out of the discussions' (1st Year). This caused 'great frustration' with some students reporting that even with the group leader translating 'it felt like we were playing (the game) broken telephone...' (1st Year student). In some groups, this caused huge rifts and it took much discussion, often mediated by the tutor and/or the lecturer to get all group members to understand that it was not an effective way of working. Students had to learn to compromise and use a common language that all group members understood as evidenced by the following: 'initially the group divisions because of language were a big problem. But we learned to work together and reach a compromise by using English' (1st Year student).

Another area of personal growth was in terms of revising gendered views. In a programme dominated by female students, the few male students report that they initially 3.Funda Ujabule is the name of the Uj-affiliated teaching school in Soweto. 
expected to make the decisions about the projects and assign roles and were quickly disavowed of this expectation by having strong female leaders. They commented as follows, 'I had to learn to change my own gendered views. I quickly learned that female students can also be strong leaders, not only males' (1st Year student). In turn, many of the female students also had their ideas of male students in a foundation phase challenged. Some of the comments in this regard were as follows: 'I saw the male students in a different way ... they can be gentle and kind when they work with the children' and:

I didn't expect to see male students working so nicely with Grade $\mathrm{R}$ children during the sports event ... I thought only females can teach very young children properly. (1st Year student)

\section{Incremental service learning: Moving beyond clinical learning}

Students report that the varied SL experiences taught them to care for others and understand that they had a responsibility to help develop a more socially just society. Third-year students mostly evidenced this in their reports. We argue that this is more likely because these students have had three years' experience of SL. For instance, a student reported:

It is my social responsibility ... my community needs me to teach the children ... but I have also learned that I need to help improve the lives of the less fortunate. It is my responsibility to inform those that do not want to contribute to uplifting others. As a teacher, I have to contribute to building my community. I need to educate community members so they too learn to do the same. (3rd Year student)

Other senior students make reference to the theoretical framework of social justice and care:

'The past political landscape of our country left the majority of our people with low levels of education or nothing at all. This leaves them stuck with low paying jobs or no income to sustain their families. This not only sets them back but our economy too.' (3rd Year student)

Through the storytelling festival in the third year, students, who interact with other schools, parents and community members in Soweto begin to understand the importance of the foundation they create in the schooling sector. In this respect, the following comments from third-year students are relevant:

'I learnt from my service learning experience that as a foundation phase teacher I hold the future of this country in my hands because I teach the future generation and as a teacher I can have a great influence on parents and other community members.' (3rd Year student)

'It is my responsibility to educate children, parents and community members about their role in sustaining and developing themselves so we can work toward empowering themselves and becoming a more socially just society.' (3rd Year student)

And:

'Many of the festival participants tell us that they didn't have a chance to learn properly at primary school and that is why they did not finish high school.' (3rd Year student)
The SL experience also provided students with unexpected learning opportunities to place themselves in the shoes of the 'other' (Bamberg \& Andrews 2004) and 'face the realities and plight of the less fortunate members of society we serve' (3rd Year student). Few students who, unbeknownst to us, chose to collect donations at a major intersection reported that the experience taught them to 'have humility as human beings' and that 'standing at the intersection begging for money forced us to go through the same torment that homeless and poor children go through on a daily basis' (3rd Year student). The students also admitted that by using this as a source of income they may have 'deprived a poor person from getting some small change' (3rd Year student).

Overall, the findings suggest that students move beyond clinical learning to developing an ethic of care as illustrated by the following: 'I now know about CARE and caring for others, I know about accountability and responsibility, I know about social justice. This I learned through my service learning' (3rd Year student).

\section{Discussion of findings}

The twinned notions of care and responsibility frame our work in teacher education. In deliberating about how to educate prospective teachers who are imbued with these intersecting ideals, we have to design learning environments in which they encounter and engage with these in a tangible way. While most teacher education programmes may easily create opportunities for students to become part of a 'cognitive apprenticeship' in an educational socio-cultural 'community of practice' (Lave \& Wenger 1991), we are concerned that students' enculturation into a 'caring apprenticeship' (Noddings 1992) is often neglected. In our view, the latter is only possible if students are encouraged to establish caring relationships in the course of their own learning. One way in which we promote this is through group work and the pedagogy of SL, through which students can learn that the concepts of care and responsibility are not to be studied in an objectified way; they are a way of being and doing. Here, we find useful the writings of Semetsky (2006:9) using Deleuze's conclusions about care theorists such as Noddings (1998:196). She proposes that (student) teachers 'become self-autonomous in the process of giving' and 'interdependence'. From this perspective, our teacher education students remain 'becoming' (in a Deleuzian sense), and find part of who they are becoming in the 'moral interdependence' of working as a team in their SL projects. Students, in groups, have to learn to become morally interdependent first with each other and then with the communities they serve. It is clear from students' reports that they initially struggle with learning how to 'serve' other members of their group. Across the three years, all students' descriptions and discourse reveal the difficulties they encounter with overcoming differing work ethics, ways of engagement and communication and working towards a goal that would benefit the community they are serving. In particular, it is clear that before students can begin to serve their community, they have to learn first how to serve each 
other by way of a caring pedagogy in interaction with group members. In addition, as a sense of care and community operate in conjunction with each other, relationships in the group have to reflect both. These relationships should be imbued, firstly, with trusting, emotional attachment, empathy and caring, and have embedded in them the discourses associated with learning to become part of a community, namely responsibility, fairness and justice. This integration is evident in the personal and professional learning expressed by students in this investigation.

Secondly, SL creates 'authentic' situations for both service and learning. The authentic situation is thus more than the physical setting in which the student enacts their service; the authenticity lies in the everyday nature of the context of the service relationship (here we would argue again, specifically first with group members) where social, ideological, cultural, political and historical elements are entwined. It is in this context where the SL groups seem to have created opportunities for students to interact within an authentic learning context and enabled their academic learning to become connected to the practices of their everyday lives. As citizens of a country where the impact of race, language and culture is still acutely felt, this is where the value of the process lies, in the ordinary practices within the particular setting of the student groups. Student reports provide ample evidence of how the socially mediated practices of this 'authentic' space can be considered to constitute a particular community of practice. Teacher education students enacting their service in this CoP are in a 'cognitive apprenticeship' that supports their learning. Students can then be considered to be on their way to becoming co-producers of knowledge, in conjunction with others through activity (and reflection). These, we would argue, are the aspects in SL that most influence students' learning and allow situated cognition to flourish.

The pedagogy of service learning also helps students take an active stance in their own learning to be foundation phase teachers and learn through experience, often from others. In this study, students learning to adopt and practise a model of care through service are evident in their experiences of care and responsibility in action with their group members. As part of a small community of practice, students also begin to view group members as 'experts' who have something to contribute to their education (Johnson \& Johnson 2000). Thus, although this is not quite the community Walshok (1999:81) refers to in SL, the small student group community is in fact also an 'invaluable source of information, evaluation, and validation of knowledge'.

\section{Conclusion}

It has been suggested by a number of SL researchers (Ender et al. 2000; Parker-Gwin \& Mabry 1998) that 'a sequence of service learning courses might maximise the potential civic and academic outcomes of service-learning [sic] for students' and build 'upon their prior experiences and better integrate their volunteer activities with course concepts and issues'. In this article, we have argued that teacher education students' struggles with learning to work in groups, in a curriculum which incorporates SL in its first three years, are instrumental in helping them establish a socio-cultural 'community of practice'. We have also argued that the group work in SL promotes a sense of community and an ethic of care that we would have been hard-pressed to teach students in a lecturerled, university classroom setup. Students' struggles in racially and linguistically mixed intact groups over three years in a pedagogy in which student experience and voice are central seem to solidify their learning about care and responsibility. In this way, students' struggles with group work acknowledge and validate students as active contributors to their own learning. This study has potential to inform curriculum design in elementary school teacher education and highlights the value of group work in SL, in particular for building CoP among student groups.

\section{Acknowledgements}

The authors would like to thank the teacher education students who took part in this study.

\section{Competing interests}

The authors declare that they have no financial or personal relationships which may have inappropriately influenced them in writing this article.

\section{Authors' contributions}

N.P. and G.P. were responsible for the project design. N.P. made substantial contributions to the conception and design. G.P. identified the research sample, collected the data and conducted preliminary analysis and interpretation. Thereafter, both authors analysed individually and then discussed the analysis before linking comparable views and concepts. N.P. drafted the manuscript. N.P. and G.P. critically revised the manuscript for important intellectual content. In essence, both authors co-wrote the manuscript.

\section{References}

Astin, A.W. \& Sax, L.J., 1998, 'How undergraduates are affected by service participation', Journal of College Student Development 39(3), 251-263.

Babbie, E. \& Mouton, J., 2015, The practice of social research, Oxford University Press, Cape Town.

Bamberg, M. \& Andrews, M. (eds.), 2004, Considering counter narratives: Narrating, resisting, making sense, J. Benjamins, Philadelphia, PA.

Berle, D., 2006, 'Incremental integration: A successful service-learning strategy', International Journal of Teaching and Learning in Higher Education 18(1), 43-48.

Boyle-Baise, M. \& Kilbane, J., 2000, 'What really happens? A look inside servicelearning for multicultural teacher education', Michigan Journal of Community Service Learning 7(1), 54-64.

Brown, J.S., Collins, A. \& Duguid, P., 1989, 'Situated cognition and the culture of learning', Educational Researcher 18(1), 32-42. https://doi.org/10.3102/0013189X018001032

Castle, J. \& Osman, R., 2003, 'Service-learning in teacher education: An institutional model for an emerging practice', South African Journal of Higher Education 17(1), 105-111. https://doi.org/10.4314/sajhe.v17i1.25199

Darling-Hammond, L., 2006, Powerful teacher education, Jossey Bass, San Francisco, CA.

De Lange, N., Mitchell, C. \& Stuart, J. (eds.), 2007, Putting people in the picture. Visual methodologies for social change, Sense, Rotterdam.

Departments of Basic Education and Higher Education and Training, 2011, Integrated strategic planning framework for teacher education and development in South za/LinkClick.aspx?fileticket=SE\%2fqk1OumtE\%3d\&tabid=677\&mid $=1898$ 
Ender, M.G., Martin, L., Cotter, D.A., Martstellar-Kowaleski, B. \& Defiore, J., 2000 'Given an opportunity to reach out: Heterogeneous participation in optional service-learning projects', Teaching in Sociology 28(3), 206-219. https://doi. org/10.2307/1318990

Eyler, J.S., Giles, D.E., Stenson, C.M. \& Gray, C.J., 2001, At a glance: What we know about the effects of service-learning on college students, faculty institutions and communities, 1993-2000, 3rd edn., Vanderbilt University, Nashille, TN.

FitzGerald, E., 2012, 'Analysing video and audio data: Existing approaches and new innovations', presentation at Surface Learning Workshop, Bristol, UK, 18-20 March.

Freeman, N.K. \& Swick, K.J., 2001, 'Early childhood teacher education students strengthen their caring and competence through service-learning', in J.B. Anderson, K.J. Swick \& J. Yff (eds.), Service-learning in teacher education: Enhancing the growt of new teachers, their students, and communities, AACTE, Washington, DC, 134-140.

Gravett, S., Petersen, N. \& Petker, G., 2014, 'Integrating foundation phase teacher education with a "teaching school" at the University of Johannesburg', Education as Change 18(1), 107-119. https://doi.org/10.1080/16823206.2013.877357

Henning, E., 1997, 'The school and its communities: Learning beyond the curriculum' South African Journal of Education 17(3), 116-124.

Henning, E., Van Rensburg, W.A. \& Smit, B., 2004, Finding your way in qualitative research, Van Schaik, Pretoria.

Johnson, G.W. \& Johnson, R.T., 2000, 'An educational psychology success story: Social interdependence theory and cooperative learning', Educational Researcher 38(5), 365-379. https://doi.org/10.3102/0013189X09339057

Lave, J. \& Wenger, E., 1991, Situated learning: Legitimate peripheral participation, Cambridge University Press, New York.

Merriam, S.B. (ed.), 2002a, Qualitative research in practice. Examples for discussion and analysis, Jossey-Bass, San Francisco, CA.

Merriam, S.B., 2002b, 'Introduction to qualitative research', in S.B. Merriam (ed.), Qualitative research in practice: Examples for discussion and analysis, pp. 3-17, Jossey-Bass, San Francisco, CA.

Mitchell, C. \& Rautenbach, S., 2005, 'Questioning service learning in South Africa: Problematising partnerships in the South African context. A case study from the University of KwaZulu Natal', South African Journal of Higher Education 19(1), 101-112.

Morton, K., 1996, 'Issues related to integrating service learning into the curriculum', in B Jacoby \& Associates (eds.), Service-learning in higher education: Concepts and practices, pp. 276-301, Jossey Bass, San Francisco, CA
Moule, P., 2005, 'E-learning for healthcare students: Developing the communities of practice framework', Ed.D. thesis, University of the West of England, Bristol.

Noddings, N., 1988, 'An ethic of caring and its implications for instructional arrangements', American Journal of Education 96(2), 215-230. https://doi. org/10.1086/443894

Noddings, N., 1992, The challenge to create care in schools: An alternative approach to education, Teachers College Press, New York.

Parker-Gwin, R. \& Mabry, J.B., 1998, 'Service learning as pedagogy and civic education: Comparing outcomes for three models', Teaching Sociology 26(4), 276-291. https://doi.org/10.2307/1318768

Petker, G. \& Petersen, N.F., 2014, 'Service learning in foundation phase teacher education: Experiential learning opportunities for student teachers', South African Journal of Childhood Education 43(3), 122-135. https://doi.org/10.4102/sajce. v4i3.231

Raskoff, S., 1997, 'Group dynamics in service-learning: Guiding student relations', Michigan Journal of Community Service Learning 4(1), 109-115.

Rowls, M. \& Swick, K.J., 2000, 'Designing teacher education course syllabi that integrate service learning', Journal of Instructional Psychology 27(3), 187-195.

Semetsky, I., 2006, Deluze, education and becoming, Sense Publishers, Rotterdam.

Swick, K. \& Brown, M., 1999, 'The caring ethic in early childhood teacher education', Instructional Psychology 26(2), 116-120.

Vogelgesang, L.J. \& Astin, A.N., 2000, 'Toward a theory of engagement: A cognitive mapping of service-learning experiences', Michigan Journal of Community Service Learning 7(1), 14-25.

Walshok, M.L., 1999, 'Strategies for building the infrastructure that supports the engaged campus', in R.G. Bringle, R. Games \& E.A Malloy (eds.), Colleges and universities as citizens, pp. 29-44, Allyn \& Bacon, Boston, MA.

Wang, W., 2000, 'Service learning: Is it good for you?', paper presented at the Annual Meeting of the American Educational Research Association Conference Roundtable, New Orleans, LA, 24-28 April.

Wenger, E., 2014, Communities of practice: A brief introduction, viewed 05 June 2016, from http://wenger-trayner.com/wp-content/uploads/2013/10/06-Briefintroduction-to-communities-of-practice.pdf

Zlotkowski, E., 1999, 'Pedagogy and engagement', in R.G. Bringle, R. Games \& E.A. Malloy (eds.), Colleges and universities as citizens, Allyn and Bacon, Boston, MA 96-120. 